Revista Brasileira de Meteorologia, v.27, n.2, 163 - 172, 2012

\title{
ESTUDO DA VARIABILIDADE ANUAL E INTRA-ANUAL DA PRECIPITAÇÃO NA REGIÃO NORDESTE DO BRASIL
}

\author{
VICENTE DE PAULO RODRIGUES DA SILVA ${ }^{1}$, EMERSON RICARDO RODRIGUES PEREIRA ${ }^{1}$, \\ RAFAELA SILVEIRA RODRIGUES ALMEIDA ${ }^{2}$
}

\author{
${ }^{1}$ Universidade Federal de Campina Grande, Unidade Acadêmica Ciências Atmosféricas, Campina Grande, \\ PB, Brasil \\ ${ }^{2}$ Universidade Estadual da Paraíba, Campina Grande, PB, Brasil
}

vicente@dca.ufcg.edu.br, ricardo@dca.ufcg.edu.br, rafinha_loka_fi@hotmail.com

Recebido Setembro de 2010 - Aceito Dezembro de 2011

\begin{abstract}
RESUMO
Este trabalho analisou as séries temporais de precipitação e do número de dias de chuva na região Nordeste do Brasil com o propósito de identificar as áreas mais susceptíveis às estiagens mais prolongadas. Os dados utilizados neste estudo foram obtidos da Agência Nacional de Águas (ANA) e da Superintendência do Desenvolvimento do Nordeste (SUDENE), para o período de 1935 a 2000. Foram construídos mapas do coeficiente de variação e do número de dias chuvosos para os períodos anual, seco e chuvoso. Os resultados deste trabalho permitiram concluir que os valores dos coeficientes de variação da precipitação e do número de dias chuvosos no semiárido são maiores do que no litoral, agreste e noroeste da região Nordeste do Brasil. Os maiores valores de coeficiente de variação são associados aos menores valores de precipitação e do número de dias chuvosos. A variabilidade da precipitação é maior no período seco do que no período chuvoso. A alta variabilidade da precipitação e do número de dias de chuva são fatores limitantes na agricultura de sequeiro nas microrregiões localizadas nas áreas semiáridas do Nordeste do Brasil.
\end{abstract}

Palavras-chave: coeficiente de variação, número de dias de chuva, períodos secos e chuvosos.

\begin{abstract}
A STUDY ON ANNUAL AND INTRA-ANNUAL VARIABILITY OF RAINFALL OVER NORTHEASTERN BRAZIL

This study analyzed rainfall and number of rainy days time series over northeastern region of Brazil with the aim of identifying areas that are more vulnerable to long periods of droughts. The data used in this study were obtained from the National Water Agency (ANA) and Superintendência do Desenvolvimento do Nordeste (SUDENE) for the period from 1935 to 2000. The variation coefficient and rainy days maps were provided for dry, wet and annual periods of the rainfall and number of rainy days. The results showed that the semiarid region have a higher variation coefficient for both rainfall and rainy days than those located at east coast, tropical thorn forest and northwest of northeastern Brazil. The highest values of the variation coefficient are associated to the lowest values of rainfall and rainy days. The rainfall variability in northeastern Brazil is higher during dry season than rainy season. The high variability in rainfall and rainy days are limiting factors to the rainfed agriculture in semiarid environments.
\end{abstract}

Keyword: variation coefficient, rainy day, dry and wet periods.

\section{INTRODUÇÃO}

A precipitação é uma das variáveis meteorológicas mais importantes do ciclo hidrológico, pois influencia várias atividades humanas, tais como, a agricultura, a pesca, a pecuária e, principalmente, o abastecimento de água para o consumo humano. Essa variável tem sido bastante estudada em diferentes regiões do mundo em face de sua importância na manutenção dos ecossistemas naturais, tal como na Guiana (Shaw, 1987); Áustria (Ehrendorfer, 1987); Estados Unidos (Guttman et al., 
1993; Arnaud et al., 2002); Iran (Modarres e Silva, 2007) e Brasil (Chaves, 1999; Chaves e Cavalcanti, 2001; Silva et al., 2003; Silva, 2004).

As secas se constituem num sério problema para a sociedade humana e para os ecossistemas naturais (Dinpashoh et al., 2004). Nesse sentido, diferentes metodologias têm sido utilizadas para analisar a variabilidade da precipitação. Silva et al. (2003) estudou a variabilidade da precipitação no Estado da Paraíba com base na teoria da entropia. Dinpashoh et al. (2004) encontraram coeficientes de variação $(\mathrm{CV})$ da precipitação pluvial no Iran variando entre $18 \%$ ao norte, onde se situam as regiões montanhosas, e 75\% no sul do país. Modarres e Silva (2007) avaliaram a tendência da precipitação pluvial também no Iran e observaram que o CV médio da região é 44,4\%. Apesar da precipitação média anual no Iran ser baixa, variando de 62,1 mm na estação de Yazd a 344,8 mm na estação de Shiraz, a sua variabilidade é baixa. Resultados semelhantes foram obtidos por Silva et al. (2003), quando analisaram a variabilidade da precipitação no Estado da Paraíba com base na teoria da entropia. Eles constataram que a variabilidade da precipitação é menor nos locais e períodos com baixa pluviosidade, do que no litoral e durante o período chuvoso no estado.

Como a variação sazonal da precipitação exerce forte influência sobre as condições ambientais, muitos pesquisadores vêm desenvolvendo estudos com base no número de dias chuvosos (Brunettia et al., 2001; Seleshi e Zanke, 2004; Zanetti et al., 2006; Modarres e Silva, 2007). Brunettia et al. (2001) observaram que o decréscimo no número de dias chuvosos na Itália é mais significativo do que a redução dos totais anuais da precipitação. Por outro lado, Silva et al. (2009), analisando a variabilidade anual e intra-anual da precipitação e do número de dias chuvosos para o Estado da Paraíba, observaram que os coeficientes de variação da precipitação e do número de dias chuvosos nas microrregiões do Cariri, Seridó e Curimataú são maiores do que nas estações localizadas nas microrregiões do litoral, agreste e brejo paraibano. Com base no número de dias com chuva (NDC) é possível se ter uma idéia da intensidade da precipitação, pois ao se analisar a chuva em intervalos de tempo distintos é possível identificar qual a sua intensidade e variabilidade espacial em termos quantitativos e qualitativos (Fischer et al., 2008).

A variabilidade da precipitação na região Nordeste do Brasil exerce forte influência na agricultura de sequeiro, que também é afetada pelas temperaturas elevadas e altas taxas de evaporação registradas na parte semiárida (Silva et al., 2006). A variabilidade intra e inter anual na precipitação é provocada por diferentes sistemas atmosféricos que atuam na região Nordeste (Silva et al., 2005), destacando-se os Vórtices Ciclônicos em Ar Superior, Distúrbios Ondulatórios de Leste, Zona de Convergência Intertropical, Zona de Convergência do Atlântico
Sul e os Sistemas Frontais. Esses fenômenos influenciam diretamente e indiretamente a ocorrência de chuvas sobre a região do Nordeste do Brasil (Graef e Haigis, 2001; Silva, 2004; Andreoli e Kayano, 2007). Além disso, entre os eventos meteorológicos no Atlântico Norte, geradores de ondas que podem atingir o litoral do Brasil, estão os ciclones extratropicais e os distúrbios africanos de leste (Innocentini et al., 2005).

A posição mais ao sul da Zona de Convergência Intertropical, nos meses de março a abril, provoca acumulados significativos de precipitação, e atinge sua posição mais ao norte nos meses de agosto e setembro, no período mais seco do norte do Nordeste (Graef e Haigis, 2001). Por outro lado, Chaves (1999), com base em dados diários de precipitação, dados da reanálise do NCEP e dados de TSM, observou que as anomalias positiva e negativa de precipitação sobre o sul do Nordeste são associadas, respectivamente, às fases positiva e negativa do fenômeno ENSO. E, ainda, que essa associação pode se dar diretamente através da variação zonal da célula de Walker ou indiretamente através dos efeitos desta variação sobre as condições atmosféricas da região Amazônica, ou ainda através de teleconexões. O padrão chuvoso está associado à intensa convecção sobre o leste da Amazônia e deslocamento da alta da Bolívia (AB) para leste, escoamento em baixos níveis da Amazônia para o sul do Nordeste e intensificação dos alísios de nordeste sobre a costa setentrional da América do Sul. No padrão seco verifica-se a $\mathrm{AB}$ a oeste da sua posição climatológica, escoamento em baixos níveis direcionado da Amazônia para latitudes ao sul e enfraquecimento dos alísios de nordeste sobre a costa norte da América da Sul (Chaves, 1999).

A Zona de Convergência do Atlântico Sul geralmente provoca chuva acima da média nas regiões Sul, Sudeste e Centro-Oeste do Brasil. Porém, quando ocorre uma variabilidade na sua posição média, esse sistema pode ocasionar anomalias de precipitação no sul da região Nordeste do Brasil (Chaves e Cavalcanti, 2001). O conhecimento da variabilidade inter e intra-anual da precipitação é bastante útil para vários propósitos, inclusive na formulação de estratégias para a implantação de culturas de sequeiro em regiões semiáridas. Dessa forma, o presente trabalho tem como objetivo analisar a variabilidade espacial da precipitação e do número de dias chuvosos na região Nordeste do Brasil, com vistas à identificação das áreas mais susceptíveis às estiagens prolongadas.

\section{MATERIAL E MÉTODOS}

\subsection{Localização da área de estudo}

A região Nordeste do Brasil (NEB) está situada entre os paralelos de $01^{\circ} 02^{\prime} 30^{\prime \prime}$ de latitude sul e $18^{\circ} 20^{\prime} 07^{\prime \prime}$ ' de latitude sul, e entre os meridianos de $34^{\circ} 47^{\prime} 30^{\prime \prime}$ e $48^{\circ} 45^{\prime} 24^{\prime \prime}$ ' a oeste do 
meridiano de Greenwich. Essa região tem por limite ao norte e ao leste o Oceano Atlântico; ao sul os Estados de Minas Gerais e Espírito Santo, e ao oeste os Estados do Pará, Tocantins e Goiás. O NEB tem uma área de $1.558 .196 \mathrm{~km}^{2}$, equivalente a $18 \%$ do território nacional, e possui a maior costa litorânea do país. Dentre os Estados nordestinos, o Estado da Bahia tem a maior costa litorânea com $932 \mathrm{~km}$ e o Estado do Piauí apenas $60 \mathrm{~km}$ de litoral.

A parte semiárida desta região corresponde a aproximadamente $60 \%$ da área total do NEB. Essa extensa área é habitada por mais de 30 milhões de pessoas e a economia é baseada principalmente na agricultura de sequeiro. O NEB é caracterizado por baixos níveis de precipitação e altas taxas de evaporação (Silva et al., 2010). A precipitação média anual varia entre $1800 \mathrm{~mm}$ na costa leste a $400 \mathrm{~mm}$ no centro do semiárido; enquanto a temperatura do ar varia entre 16,8 a $33,8{ }^{\circ} \mathrm{C}$ e a evaporação pode ultrapassar $10 \mathrm{~mm} \mathrm{~d}^{-1}$ (Silva et al., 2006). A Figura 1 exibe a espacialização dos postos pluviométricos utilizados no estudo e a Figura 2 a distribuição espacial da precipitação média anual na região Nordeste do Brasil, evidenciando a parte semiárida no centro da região com precipitação anual inferior a $500 \mathrm{~mm}$ anuais. $\mathrm{O}$ tipo de vegetação predominante é caatinga e o solo é bastante diversificado, formado principalmente por Lotossolo arenoso (Silva, 2004).

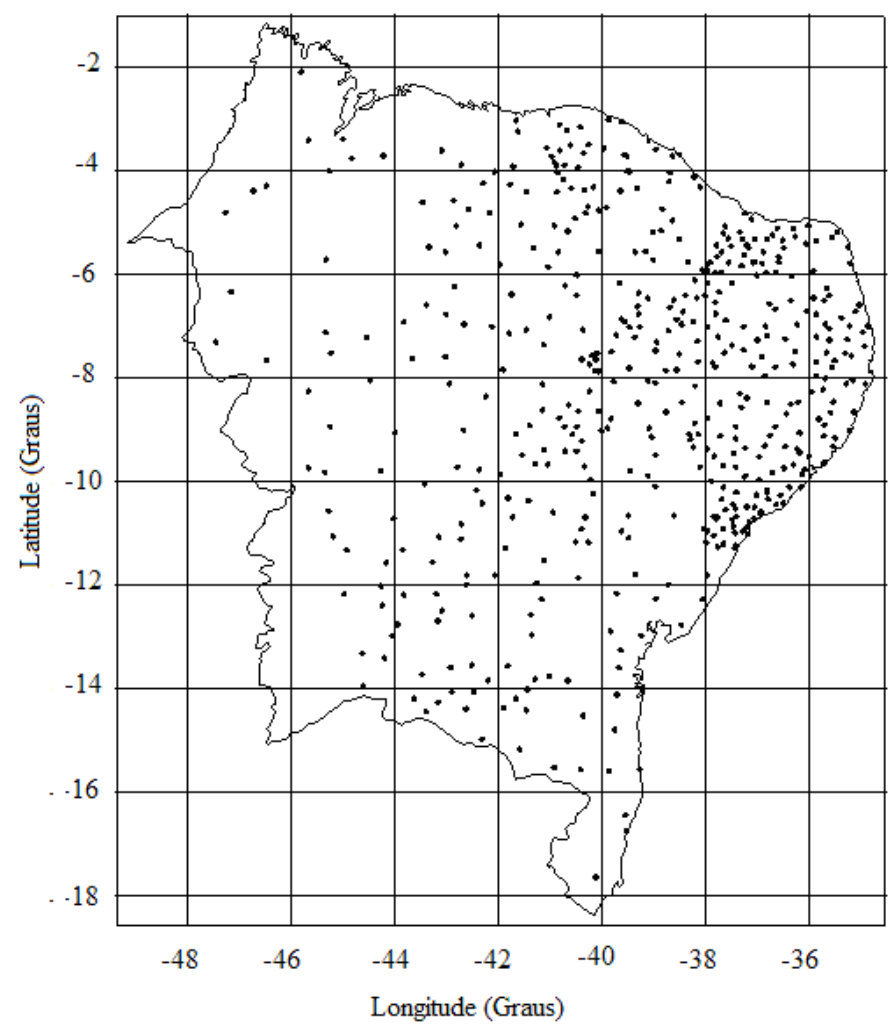

Figura 1 - Espacialização dos postos pluviométricos utilizados no estudo.

\subsection{Dados e análise estatística}

Neste estudo foram utilizados dados de 600 postos pluviométricos localizados nos 9 estados da região Nordeste do Brasil, com mais de 30 anos de dados. Foi considerado como dia chuvoso aquele com precipitação acima de $0,1 \mathrm{~mm}$. Os dados utilizados neste estudo foram obtidos da Agência Nacional de Águas (ANA) e da Superintendência do Desenvolvimento do Nordeste (SUDENE), para o período mínimo de 30 anos, variando em geral de 1935 a 2000. Foram estabelecidas séries temporais dos totais pluviométricos em todos os postos selecionados, para todo o período de análise, sendo que as falhas de observação foram preenchidas por correlação com postos do mesmo grupo, adotando-se o critério de proximidade e considerando as eventuais diversidades climáticas existentes. Para análise de consistência dessas séries pluviométricas, foram elaboradas curvas duplo-acumulativas. Foram construídos mapas para a espacialização do coeficiente de variação e do número de dias chuvosos para a precipitação anual e os períodos seco e chuvoso sob a região de estudo. Na determinação dos períodos seco e chuvoso foram construídos histogramas de freqüências das séries temporais mensais da precipitação pluvial para cada posto pluviométrico, e identificados os quatros meses mais chuvosos e os quatros meses mais secos.

\subsection{Coeficiente de variação}

$\mathrm{O}$ coeficiente de variação $(\mathrm{CV})$ para cada série foi calculado pela relação entre o desvio padrão e a média aritmética.

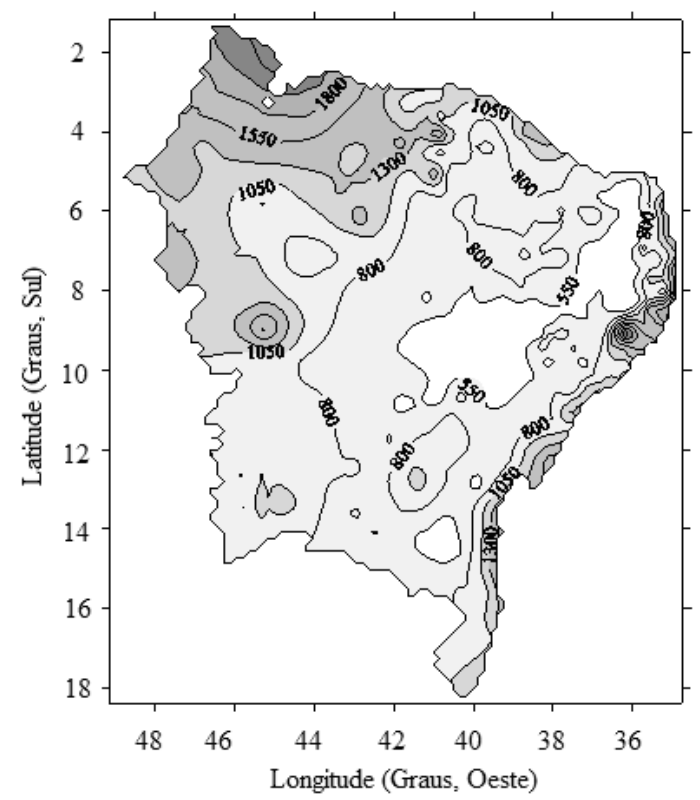

Figura 2 - Distribuição espacial da precipitação média anual na região Nordeste do Brasil. 
O CV (\%) é uma medida de dispersão da variável analisada, sendo obtido pela Equação 1 (Silva et al., 2009):

$$
\mathrm{CV}=\frac{\sigma}{\mu} 100
$$

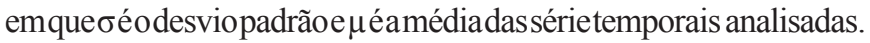

\subsection{Função de autocorrelação}

A aleatoriedade dos dados das séries temporais foi avaliada com base na função de autocorrelação para os intervalos de confiança dada pela Equação 2 (Modarres e Silva, 2007):

$$
\mathrm{CB}=\frac{\mathrm{Z}_{\mathrm{i}}-\alpha / 2}{\sqrt{\mathrm{n}}},
$$

em que $\mathrm{Z}$ é a função da distribuição normal, $\mathrm{n}$ é o tamanho da amostra e $\alpha$ é o nível de significância. O intervalo de confiança depende do tamanho de amostra. Os métodos de análise de séries temporais no domínio do tempo procuram caracterizar as séries de dados nos mesmos termos em que são observados e registrados. A ferramenta principal para a caracterização da relações entre valores de dados na aproximação do domínio temporal é a função de autocorrelação ou coeficiente de correlação serial.

A autocorrelação pode ser definida como o grau de variação comum entre uma variável $(\mathrm{X})$ medida no tempo $\mathrm{t}$ com ela mesma medida num tempo posterior $\mathrm{t}+\mathrm{k}$, onde $\mathrm{k}$ é o tempo do intervalo de observação. A autocorrelação mede a persistência de uma onda dentro de uma série temporal. Quando a autocorrelação é próxima de zero ela informa que há um processo randômico ocorrendo sem nenhuma persistência ou regularidade. A autocorrelação é normalmente calculada para um lag (um intervalo de defasagem) de variação e o resultado é plotado em um gráfico que inclui os valores obtidos versus $\mathrm{K}$ intervalos de observação da variável. Para o caso especial do lag zero, que corresponde ao cálculo da autocorrelação da série sem defasagem com ela mesma, o resultado é 1 . O gráfico da função autocorrelação versus lag é chamado de correlograma, sendo bastante útil para determinar se sucessivas observações são independentes. Se o correlograma indicar alta correlação entre $\mathrm{X}(\mathrm{t})$ e $\mathrm{X}(\mathrm{t}+\tau)$, as observações não podem ser assumidas como independentes (Modarres e Silva, 2007). Dessa forma, a função de autocorrelação pode indicar a memória de um processo estocástico.

\section{RESULTADOS E DISCUSSÃO}

Os mapas de isolinhas do número de dias de chuva e dos coeficientes de variação (CVs) da precipitação no Nordeste do Brasil (NEB), para os períodos secos e chuvosos e para os totais anuais, são apresentados nas Figuras 3 a 5. Nas localidades em que a precipitação é baixa ocorreram valores de CVs altos; e para as localidades em que a precipitação é alta os valores de CVs foram baixos. Resultados semelhantes foram obtidos por Dinpashoh et al. (2004) em um estudo realizado para o Iran, em que os valores da média da precipitação são inversamente proporcionais aos valores dos CVs. A análise dos resultados revela ainda que a distribuição espacial da precipitação e do número de dias chuvosos para o NEB não é uniforme, ou seja, varia sensivelmente de acordo com a localização geográfica. Os resultados obtidos por Chaves (1999) indicam que a maior parte do sul do Nordeste apresenta baixo índice pluviométrico e alta variabilidade espacial e temporal. As análises de cada período de estudo são apresentadas a seguir.

\subsection{Período anual}

A distribuição espacial do número de dias de chuva no NEB, bem como, o coeficiente de variação temporal da
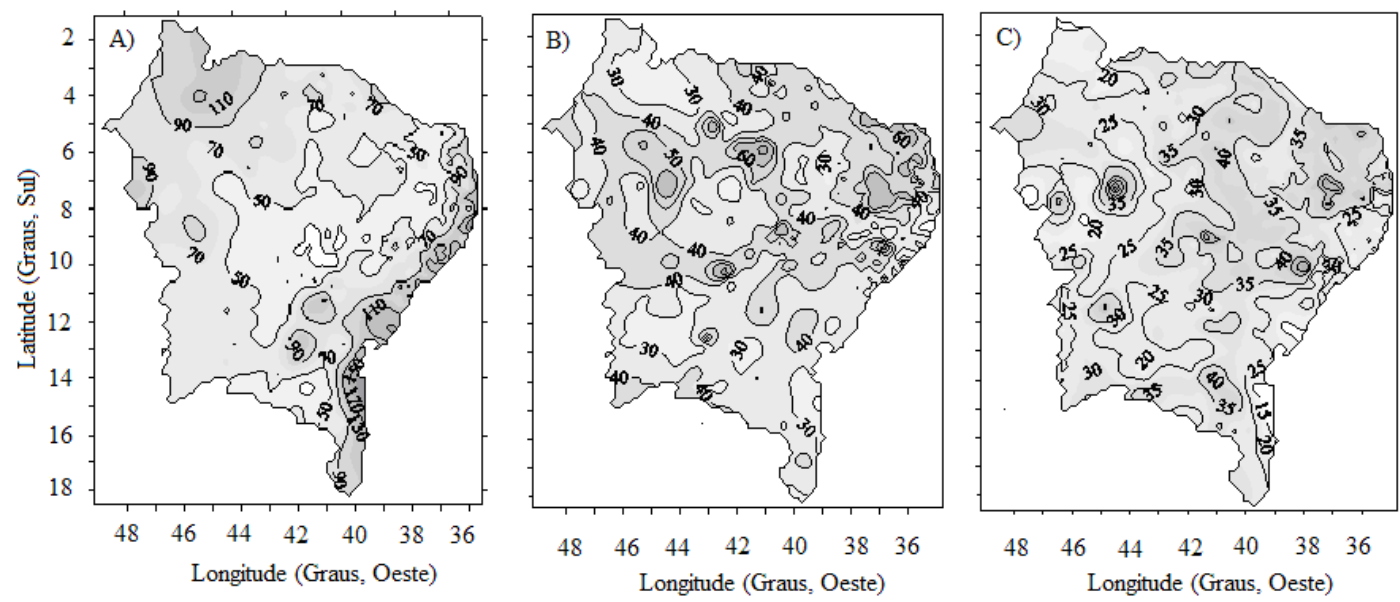

Figura 3 - Distribuição espacial do número de dias com chuva (A), coeficiente de variação temporal (\%) da precipitação (B) e do número de dias com chuva (C) no Nordeste do Brasil referente ao período anual. 
precipitação e do número de dias de chuva, referente ao período anual é exibida na Figura 3. No período estudado, o maior NDC se concentra na costa leste e agreste, entre os Estados da Bahia a Paraíba, com valores entre 90 e 170 dias, bem como no norte e noroeste da região (Rio G. do Norte, Ceará e Maranhão) com valores entre 70 e 120 dias (Figura 3A). No semiárido nordestino foram encontradas as menores médias dos números de dias com chuva, com valores menores do que 50 dias. Os valores de CVs são muito baixos na zona da mata (Litoral) e agrestes nordestino para as duas variáveis analisadas, variando entre 20 e $60 \%$ para precipitação e entre 15 e $45 \%$ para o número de dias com chuva. No noroeste do NEB, os valores de CVs variaram entre 30 e $60 \%$ para precipitação (Figura 3B), e entre 20 e $45 \%$ para o NDC (Figura 3C). Na parte semiárida, os valores dos CVs variaram entre 35 e $90 \%$ para precipitação e entre 25 e $80 \%$ para o NDC. Os maiores valores dos CVs para ambas variáveis estão localizados na área semiárida, entre o sul do Estado do Ceará e o norte do Estado de Minas Gerais. Por outro lado, os menores valores de CV são encontrados na costa do NEB. Os altos valores dos CVs da precipitação e do número de dias de chuvas no semiárido são associados à alternância de períodos secos e chuvosos, provocados pelos eventos de El Niño e La Niña, que ocorrem de forma recorrente na região. Valores semelhantes de CVs foram encontrados no Iran por Dinpashoh et al. (2004), com coeficientes de variação da precipitação variando entre $18 \%$ ao Norte, onde se situam as regiões montanhosas, e $75 \%$ no Sul do país.

Os baixos valores dos CVs na costa leste do NEB são associados à regularidade dos sistemas atmosféricos atuantes nessa parte da região, tais como, os Vórtices Ciclônicos em Ar Superior, Distúrbios Ondulatórios de Leste e os Sistemas Frontais. Resultados semelhantes foram obtidos por Chaves (1999), que observou maior variabilidade temporal da precipitação na parte nordeste, central e sudoeste do setor sul do Nordeste e norte de Minas Gerais. Essa autora constatou, ainda, que os índices mais baixos de variabilidade da precipitação anual são encontrados nas áreas litorâneas, devido às características dos sistemas atmosféricos atuantes nessa parte do NEB, fazendo com que os totais anuais de precipitação tenham tendência de não ser tão dispersivos em relação à média climatológica.

\subsection{Período chuvoso}

As distribuições espaciais do NDC no NEB, do coeficiente de variação temporal da precipitação e do NDC, referente ao período chuvoso, são exibidas na Figura 4. Como não existe um período chuvoso uniforme sobre o NEB, foi determinada a estação chuvosa para cada posto analisado, utilizado a metodologia anteriormente mencionada.

O maior NDC durante o período chuvoso se concentra na Zona da Mata (Litoral) e Agreste do NEB, com valores variando entre 9 e 20 dias; em seguida decresce em direção ao interior da região, com valores inferiores a 9 dias (Figura 4A). No setor noroeste esses valores são maiores que 15 dias; no semiárido nordestino foram encontrados os menores valores de números de dias com chuva, atingindo no máximo 12 dias, especificamente na região que compreende os municípios de Cabaceiras e Serra Branca no Cariri paraibano. Durante o período chuvoso, os valores baixos dos coeficientes de variação da precipitação (Figura 4B) e do número de dias de chuva (Figura 4C) são encontrados também no litoral leste e agreste nordestino. Já os maiores valores dessas variáveis foram encontrados no semiárido da região. Os valores de CVs são maiores para precipitação, do que para o número de dias de chuva. Utilizando metodologia semelhante para o Estado do Rio Grande do Sul, Fischer et al. (2008) obtiveram valores de coeficiente de variação do NDC variando de 21 a $36,9 \%$ para a série de dados observada e entre 18,7 a $39,6 \%$ para a série de dados prevista com base na temperatura da superfície do mar.
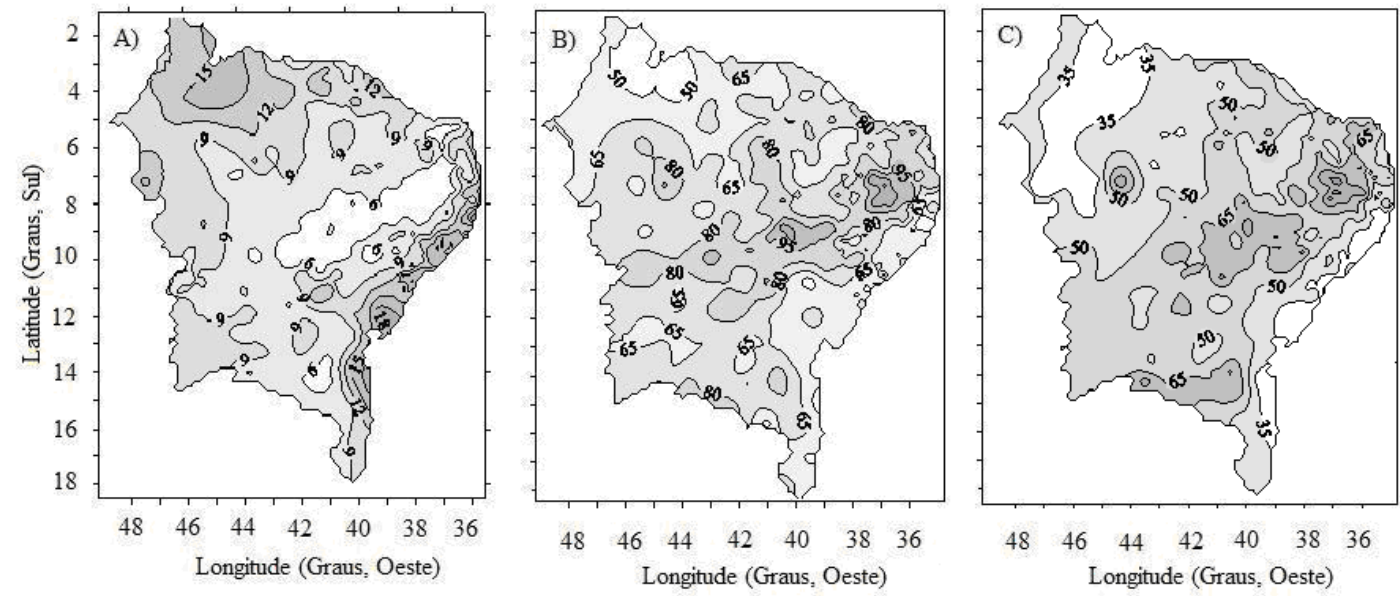

Figura 4 - Distribuição espacial do número de dias com chuva (A), coeficiente de variação temporal (\%) da precipitação (B) e do número de dias com chuva (C) no Nordeste do Brasil referente ao período chuvoso. 


\subsection{Período seco}

Na Figura 5 é apresentada a distribuição espacial do NDC e o coeficiente de variação temporal da precipitação e do NDC no NEB referente ao período seco. Nesse período, o maior NDC na região de estudo se concentra na faixa litorânea, sendo crescente do litoral norte para o litoral sul da região, com valores entre 3 e 10 dias; em seguida decresce em direção ao interior do NEB com valores entre 1 e 3 dias, atingindo o mínimo no centro da região semiárida (Figura 5A). No semiárido do NEB foram encontrados valores do número de dias de chuva entre 0 e 3 dias. Essa parte do NEB é a mais seca dentre todas as regiões nordestinas durante todo período do ano (Silva, 2004).

Na parte semiárida da região se verificam os maiores valores de CVs, entre 140 e 300\% para precipitação (Figura 5B) e entre 120 e $280 \%$ para o número de dias de chuva (Figura 5C). Já no noroeste do NEB, os valores de CVs variaram entre 100 e $200 \%$ para a precipitação e entre 70 e $150 \%$ para o NDC. Por outro lado, a faixa litorânea apresentou valores de CVs variando entre 60 e $140 \%$ para precipitação e entre 40 e $120 \%$ para o NDC. Também no período seco, os valores de CVs da precipitação foram maiores do que aqueles apresentados pelo NDC. Esses resultados indicam que a variabilidade da precipitação é maior nos períodos secos e nas regiões com menor pluviosidade. A razão disso está associada à presença de eventos de chuva mesmo no período seco e em regiões com baixa pluviosidade, em face dos altos valores dos desvios padrão, que podem chegar a $80 \%$ da precipitação média anual. Chaves (1999) constatou que nas partes nordeste, central e sudoeste do setor sul do Nordeste e norte de Minas Gerais, o desvio padrão da precipitação anual corresponde aproximadamente a $40 \%$ da precipitação média anual.

\subsection{Valores médios do NDC e do coeficiente de variação}

Os valores das médias mensal, anual e dos períodos chuvoso e seco do NDC, dos coeficientes de variação da precipitação e do NDC, em cada estado do NEB, são apresentados nas Tabelas 1 a 3. Os maiores valores médios do NDC se concentram, em sua maior parte, nos estados localizados no norte do NEB no período de janeiro a junho (Tabela 1).

Para o Estado do Maranhão se observa que a média mensal do NDC variou entre 2 dias, no período seco, a 16 dias no período chuvoso. Os Estados do Maranhão, Piauí e Ceará apresentam os maiores valores médios mensais do NDC nos meses de fevereiro a março; enquanto que os menores valores foram para o período seco de julho a setembro para os Estados do Maranhão e Piauí e de agosto a outubro para o Estado do Ceará. Os Estados do Piauí e Ceará apresentam a menor média mensal do NDC durante a estação seca dentre todos os estados do NEB. Como mencionado anteriormente, a estação chuvosa nos Estados do Ceará, R. G. do Norte, Paraíba e Pernambuco culmina nos meses de março e abril. Por outro lado, as áreas desde o leste do Rio Grande do Norte até o sul da Bahia recebem a máxima precipitação durante o período de maio e junho, e são influenciadas pelo escoamento médio e brisas terra-mar (Ramos, 1975), pelos aglomerados convectivos que se propagam para oeste (Yamazaki e Rao, 1977), além dos vórtices ciclônicos de ar superior e sistemas frontais remanescentes na parte sul (Kousky e Gan, 1981).

A estação chuvosa em todos os estados do norte do NEB culmina com a época do ano em que a ZCIT está mais ao Sul, que corresponde aos meses de fevereiro, março e abril, ou seja, o trimestre chuvoso (Uvo e Nobre, 1989). A estação chuvosa nessa área do NEB é coincidente com a posição mais sul da ZCIT (Ratisbona, 1976) e com o aparecimento de Linhas de
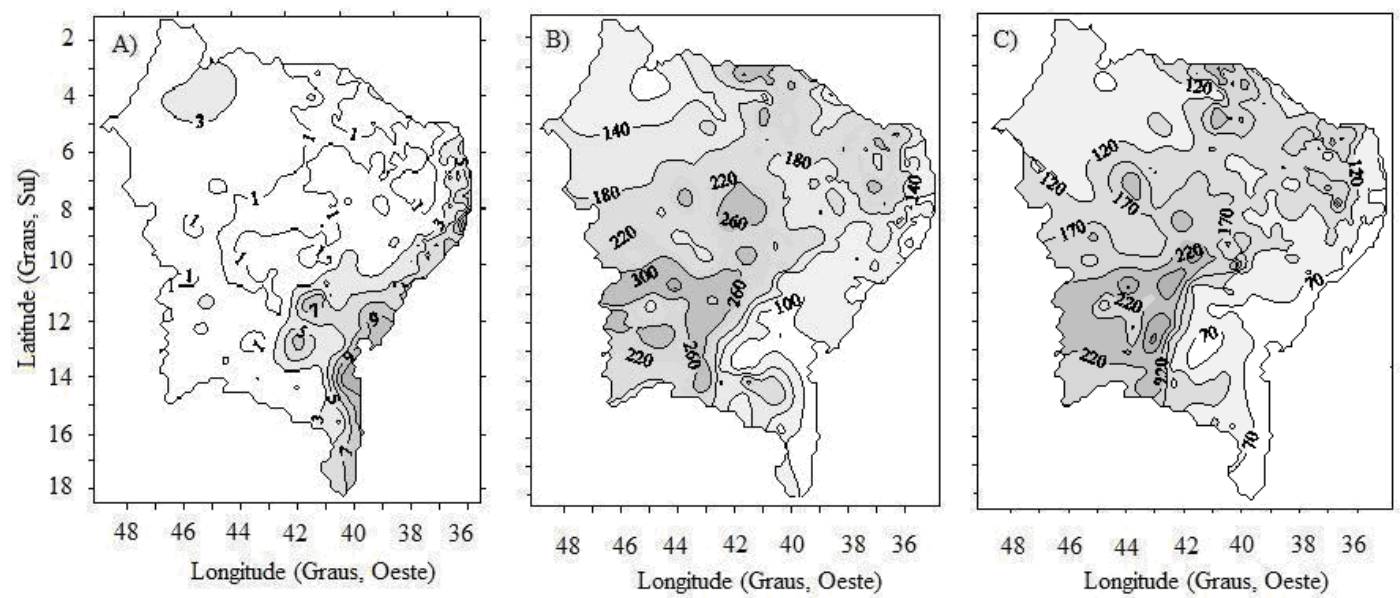

Figura 5 - Distribuição espacial do número de dias com chuva (A), coeficiente de variação temporal (\%) da precipitação (B) e do número de dias com chuva (C) no Nordeste do Brasil referente ao período seco. 
Instabilidade. Entretanto, os estados localizados na costa leste da região sofrem a influência de outros sistemas atmosféricos, tais como, os vórtices ciclônicos de ar superior e ondas de leste. Assim, os Estados do Rio Grande do Norte, Paraíba e Pernambuco têm o trimestre chuvoso nos meses de março a maio e seco de setembro a novembro. O Estado do Ceará, a microrregião do sertão do R. G. do Norte, os interiores dos Estados da Paraíba e Pernambuco estão inseridos no semiárido nordestino onde a estação chuvosa, em sua maior parte, culmina com a época do ano em que a ZCIT está mais ao Sul, que corresponde aos meses de março e abril (Aldaz, 1971).

No trimestre chuvoso, os valores médios mensais do NDC são de 10, 9 e 7 dias, respectivamente, para os Estados do Rio Grande do Norte, Paraíba e Pernambuco; enquanto que durante a estação seca o NDC varia entre 2 e 5 dias nesses estados. Portanto, o trimestre chuvoso nesses estados se desloca um mês em relação aos estados localizados mais ao norte do NEB. Por outro lado, os Estados de Alagoas e Sergipe têm o trimestre chuvoso centrado nos meses de maio a julho, com valores médios mensais do NDC durante a estação chuvosa de 15 dias e durante a estação seca de 4 dias em ambos os estados. Assim, além do maior número de dias chuvosos, esses estados têm a estação chuvosa deslocada dois meses em relação aos Estados do Rio Grande do Norte, Paraíba e Pernambuco. Nesse estudo não foram identificadas com precisão as estações chuvosa e seca no Estado da Bahia, em face, possivelmente, de sua grande extensão territorial, que possui três períodos chuvosos distintos. Na maior parte desse estado predomina a estação seca e fria, que vai de maio a setembro, e a estação chuvosa e quente, que vai de outubro a abril. Especificamente, a precipitação no interior da Bahia ocorre de novembro a março, com um máximo em dezembro e está associada com as incursões dos sistemas frontais na direção equatorial. Ainda existem algumas áreas em que os regimes de precipitação apresentam dois máximos anuais, resultantes da existência de distúrbios de escala sinótica que atuam em épocas distintas. Isso ocorre no setor centro norte do Estado da Bahia, entre os meses de dezembro e março, e no seu litoral, entre os meses de dezembro e maio (Kousky, 1979).

Na Tabela 2 são apresentados os valores médios dos CVs da precipitação mensal, anual e para as estações chuvosas e secas nos 9 estados do Nordeste do Brasil. Os menores valores dos CVs estão localizados em sua maior parte no primeiro semestre do ano em face da estação chuvosa da região se concentrar basicamente nesse período.

Para o Estado do Maranhão, verificaram-se valores médios do CV da precipitação variando entre $45 \%$ no mês de março a $168 \%$ no mês de agosto; para o Estado do Piauí a variabilidade da precipitação é bem maior, variando de 66 a $312 \%$ nos mesmos meses dos períodos chuvoso e seco, respectivamente. Também para os Estados do Ceará, R. G. do Norte, Paraíba e Pernambuco os menores valores dos CVs ocorreram no mês de março; enquanto os maiores, que ocorreram no trimestre seco, aparecem nos meses de setembro ou outubro. Tal como para o número de dias chuvosos, para os Estados de

Tabela 1 - Média mensal, anual e dos períodos chuvoso e seco do número de dias com chuva em cada estado da região Nordeste do Brasil.

\begin{tabular}{|c|c|c|c|c|c|c|c|c|c|c|c|c|c|c|c|}
\hline Meses/estados & Jan & Fev & Mar & Abr & Mai & Jun & Jul & Ago & Set & Out & Nov & Dez & Anual & Chuvoso & Seco \\
\hline Maranhão & 14 & 15 & 18 & 16 & 10 & 5 & 3 & 2 & 2 & 4 & 5 & 8 & 102 & 16 & 2 \\
\hline Piauí & 9 & 11 & 12 & 10 & 4 & 2 & 1 & 1 & 1 & 3 & 5 & 6 & 65 & 11 & 1 \\
\hline Ceará & 7 & 10 & 14 & 13 & 8 & 4 & 2 & 1 & 1 & 1 & 1 & 3 & 65 & 12 & 1 \\
\hline R.G. do Norte & 5 & 7 & 11 & 11 & 8 & 6 & 5 & 5 & 5 & 5 & 4 & 4 & 76 & 10 & 5 \\
\hline Paraíba & 4 & 6 & 9 & 9 & 8 & 7 & 6 & 4 & 3 & 2 & 2 & 3 & 63 & 9 & 2 \\
\hline Pernambuco & 5 & 6 & 8 & 7 & 7 & 7 & 7 & 4 & 3 & 2 & 3 & 4 & 63 & 7 & 3 \\
\hline Alagoas & 5 & 5 & 8 & 11 & 14 & 15 & 16 & 12 & 8 & 5 & 3 & 4 & 106 & 15 & 4 \\
\hline Sergipe & 4 & 6 & 8 & 11 & 15 & 15 & 16 & 13 & 8 & 5 & 4 & 4 & 109 & 15 & 4 \\
\hline Bahia & 6 & 6 & 9 & 7 & 6 & 5 & 5 & 5 & 4 & 4 & 7 & 7 & 71 & 7 & 4 \\
\hline
\end{tabular}

Tabela 2 - Média mensal, anual e dos períodos chuvoso e seco do coeficiente de variação (\%) da precipitação (mm) em cada estado da região Nordeste do Brasil.

\begin{tabular}{|c|c|c|c|c|c|c|c|c|c|c|c|c|c|c|c|}
\hline Meses/estados & Jan & Fev & Mar & $\mathrm{Abr}$ & Mai & Jun & Jul & Ago & Set & Out & Nov & Dez & Anual & Chuvoso & Seco \\
\hline Maranhão & 58 & 52 & 45 & 58 & 76 & 117 & 157 & 168 & 137 & 115 & 93 & 80 & 34 & 57 & 140 \\
\hline Piauí & 71 & 69 & 66 & 79 & 128 & 213 & 290 & 312 & 235 & 141 & 106 & 92 & 44 & 62 & 213 \\
\hline Ceará & 84 & 70 & 52 & 61 & 80 & 106 & 138 & 224 & 245 & 239 & 209 & 135 & 40 & 66 & 192 \\
\hline R.G. do Norte & 99 & 94 & 67 & 75 & 85 & 98 & 126 & 194 & 236 & 309 & 263 & 171 & 51 & 76 & 215 \\
\hline Paraíba & 96 & 93 & 84 & 85 & 90 & 102 & 119 & 202 & 206 & 243 & 213 & 162 & 53 & 92 & 187 \\
\hline Pernambuco & 94 & 90 & 74 & 84 & 102 & 108 & 129 & 183 & 183 & 168 & 123 & 113 & 38 & 77 & 159 \\
\hline Alagoas & 97 & 96 & 93 & 75 & 68 & 62 & 65 & 73 & 86 & 133 & 131 & 135 & 41 & 62 & 115 \\
\hline Sergipe & 98 & 98 & 90 & 73 & 66 & 54 & 55 & 57 & 80 & 107 & 128 & 115 & 35 & 57 & 101 \\
\hline Bahia & 93 & 92 & 92 & 93 & 141 & 198 & 206 & 226 & 173 & 118 & 84 & 88 & 37 & 73 & 181 \\
\hline
\end{tabular}


Alagoas e Sergipe ocorre um deslocamento dos valores extremos dos CVs da precipitação em relação aos estados localizados mais ao norte da região. Os menores CVs são encontrados em junho e os maiores nos meses de novembro ou dezembro. Os valores médios do $\mathrm{CV}$ da precipitação durante os períodos anual e chuvoso representam 41 e $69 \%$, respectivamente, daquele do período seco; entretanto, a variabilidade do trimestre chuvoso é maior do que a do período anual, em aproximadamente $28 \%$.

Os valores médios dos CVs do NDC durante os períodos mensal, anual, chuvoso e seco para os estados do NEB são exibidos na Tabela 3. Assim como, para o CV de precipitação, os menores valores dessa variável estão localizados no mês de março para os estados localizados na parte norte e na costa leste do NEB com penetração no semiárido, como os Estados da Paraíba e Pernambuco. Entretanto, para os Estados de Alagoas e Sergipe os menores CVs aparecem no mês de maio e não em junho, como ocorreu com a precipitação. Em média para todo o $\mathrm{NEB}$, os CVs do número de dias chuvosos durante os trimestres chuvoso e seco representam, respectivamente, 14,2 e 3,6\% do CV médio do período anual. Por outro lado, a variabilidade do NDC durante o trimestre chuvoso é $292 \%$ maior do que no período seco. Portanto, a variabilidade da precipitação é maior do que aquela do NDC no NEB, durante os períodos seco e chuvoso; entretanto, para o período anual o NDC apresenta uma variabilidade maior do que a precipitação, que em média é de $93 \%$. A variabilidade da precipitação e do NDC não é uniforme no Nordeste do Brasil, em face dos diferentes períodos chuvosos e secos na região provocados pela incidência de diferentes fenômenos atmosféricos em épocas distintas do ano.

A função de autocorrelação aplicada às séries temporais de precipitação indicou poucos valores significativos nas autocorrelações para o limite de $95 \%$ de confiança. Neste estudo, a função de autocorrelação foi calculada a partir das séries temporais dos totais anuais de um posto pluviométricos para cada estado do NEB no período de 1935 a 2000. O posto pluviométrico da Ponte BR 222, no Estado do Maranhão, não apresentou nenhum valor significativo de autocorrelação (Figura $6 \mathrm{~A}$ ); portanto, essa série temporal apresenta um comportamento quase aleatório. Analisando os correlogramas para o Estado do Piauí (Figura 6B), verificou-se que a série temporal do posto pluviométrico de Nazaré do Piauí apresenta também comportamento quase aleatório. No posto de Brejo dos Santos, no Estado do Ceará, o valor da autocorrelação de lag 10 é significativo, destacando-se persistência de cinco anos (Figura 6C); enquanto os outros valores do correlograma se apresentam de forma quase aleatória. Os valores de autocorrelação do posto pluviométrico de Apodi, no Rio Grande do Norte, não apresentam qualquer persistência nos dados (Figura 6D).

Os valores de autocorrelação do posto pluviométrico de Taperoá, no Estado da Paraíba, revelam que a série temporal não apresenta picos significativos (Figura 6E). Esses baixos valores das autocorrelações implicam em fraca memória ou fraca persistência anual dos eventos de chuva no Estado. Analisando o correlograma do posto pluviométrico de Malhada Real, no Estado de Pernambuco (Figura 6F), nota-se certa similaridade com o posto do Paraíba. A série temporal de chuvas nesse posto não exibe nenhum grau de dependência entre as observações. Por outro lado, o posto de Quebrângulo, no Estado de Alagoas, apresenta valores de autocorrelação significativos e positivos para os lags de 1 a 5 (Figura 6G), indicando que a série temporal é estacionária e persistente, com dependência de 5 anos. Esse fato sugere certa normalidade do período chuvoso nesse posto pluviométrico. O posto pluviométrico de Bonfim, no Estado de Sergipe, apresenta valores de autocorrelação significativos para os primeiros lags (Figura $6 \mathrm{H}$ ). A série temporal exibida nesse correlograma é estacionária, com curto período de correlação e com comportamento autoregressivo de ordem 1 ou 2. O posto de Lagoa Preta, no Estado da Bahia, exibe valores de autocorrelação sem nenhuma significância estatística (Figura 6I), indicando que o comportamento dos eventos de precipitação anual é também quase aleatório.

\section{CONCLUSÃO}

Os resultados deste trabalho permitem concluir que a variabilidade da precipitação na região de estudo é menor no

Tabela 3 - Média mensal, anual e dos períodos chuvoso e seco do coeficiente de variação (\%) do número de dias com chuva em cada estado da região Nordeste do Brasil.

\begin{tabular}{lrrrrrrrrrrrrrrr}
\hline Meses/estados & Jan & Fev & Mar & Abr & Mai & Jun & Jul & Ago & Set & Out & Nov & Dez & Anual & Chuvoso & Seco \\
\hline Maranhão & 35 & 32 & 26 & 36 & 52 & 86 & 116 & 120 & 98 & 79 & 64 & 51 & 25 & 35 & 101 \\
Piauí & 48 & 45 & 41 & 54 & 92 & 149 & 220 & 240 & 156 & 100 & 70 & 65 & 32 & 48 & 157 \\
Ceará & 63 & 53 & 37 & 43 & 59 & 83 & 111 & 181 & 202 & 193 & 157 & 102 & 34 & 48 & 150 \\
R.G. do Norte & 87 & 71 & 50 & 54 & 62 & 77 & 98 & 147 & 186 & 235 & 192 & 125 & 43 & 57 & 163 \\
Paraíba & 82 & 76 & 57 & 60 & 65 & 74 & 86 & 121 & 145 & 171 & 145 & 111 & 43 & 68 & 135 \\
Pernambuco & 64 & 67 & 54 & 61 & 75 & 83 & 97 & 144 & 134 & 118 & 90 & 79 & 33 & 56 & 118 \\
Alagoas & 68 & 72 & 58 & 48 & 41 & 35 & 38 & 45 & 59 & 93 & 89 & 85 & 28 & 39 & 77 \\
Sergipe & 68 & 68 & 58 & 45 & 39 & 35 & 34 & 39 & 55 & 72 & 75 & 74 & 25 & 37 & 66 \\
Bahia & 69 & 66 & 65 & 67 & 110 & 167 & 161 & 195 & 135 & 84 & 60 & 62 & 31 & 57 & 152 \\
\hline
\end{tabular}



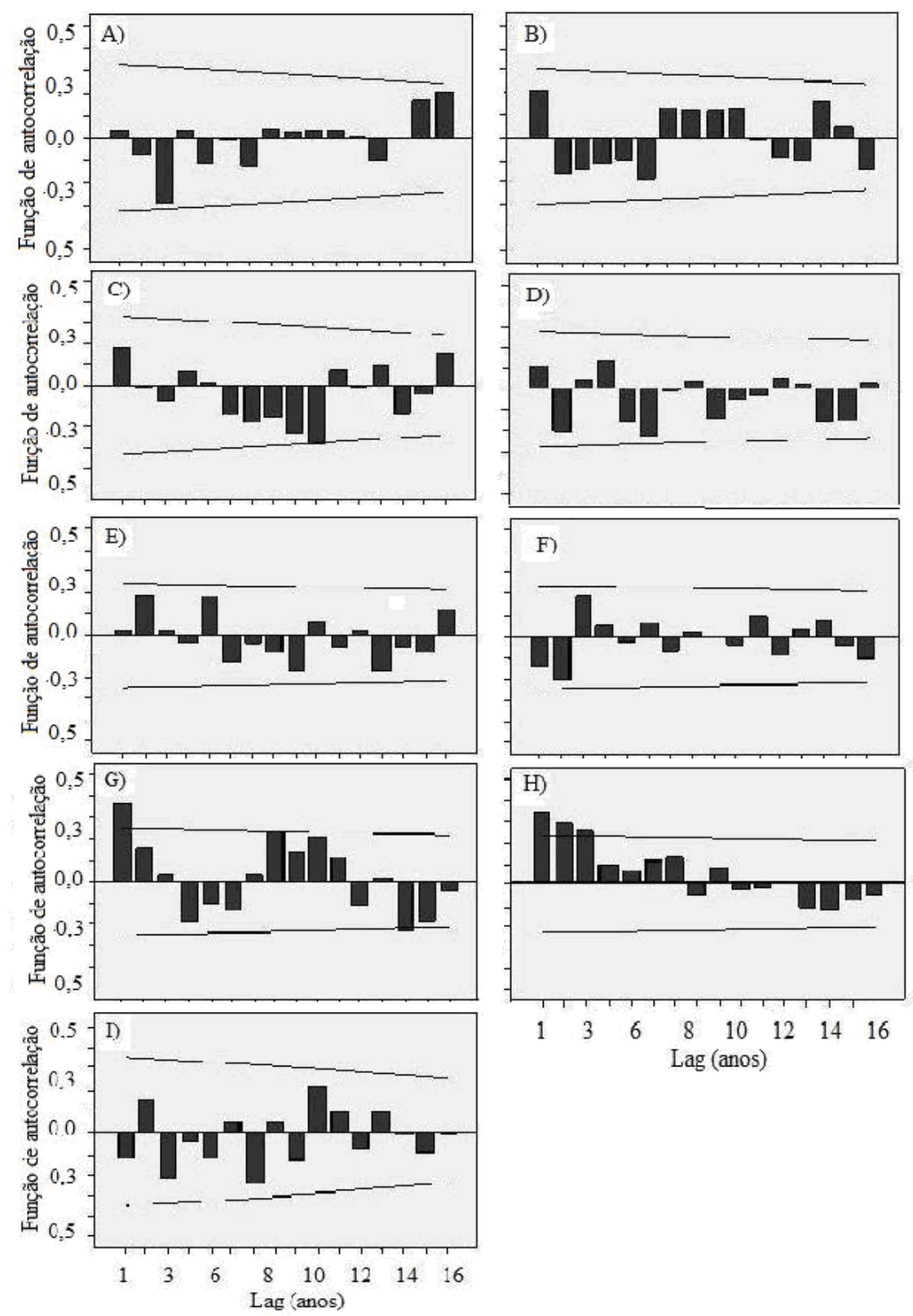

Figura 6 - Função de autocorrelação para os postos pluviométricos: (A) Ponte BR 222 - MA, (B) Nazaré do Piauí - PI, (C) Brejo dos Santos - CE, (D) Apodi - RN, (E) Taperoá - PB, (F) Malhada Real - PE, (G) Quebrângulo - AL, (H) Bonfim - SE e (I) Lagoa Preta - BA. As linhas superiores e inferiores constituem o limite de $95 \%$ de confiança.

período chuvoso do que no período seco e que os maiores valores do coeficiente de variação são associados aos menores valores de precipitação e número de dias de chuva. Os valores médios do CV da precipitação durante os períodos anual e chuvoso representam 41 e $69 \%$, respectivamente, daquele do período seco; entretanto, a variabilidade do trimestre chuvoso é maior do que a do período anual, em aproximadamente $28 \%$. Por outro lado, a variabilidade da precipitação é maior do que aquela observada no NDC no NEB, durante os períodos seco e chuvoso; entretanto, para o período anual o número de dias chuvosos apresenta uma variabilidade maior do que a precipitação, em média de $93 \%$. A alta variabilidade da precipitação e do número de dias de chuva são fatores limitantes na agricultura de sequeiro nas microrregiões localizadas nas áreas semiáridas do Nordeste do Brasil. A função de autocorrelação aplicada às séries temporais de precipitação indicou comportamento quase aleatório, com poucos valores significativos nas autocorrelações das séries de chuva no NEB para o limite de $95 \%$ de confiança. A maior média do NDC durante o período chuvoso se concentra na Zona da Mata e Agreste do NEB e decresce em direção ao 
interior da região. No semiárido do NEB são encontrados os menores valores de números de dias de chuva, atingindo em média no máximo 12 dias no período anual, especificamente na região que compreende os municípios de Cabaceiras e Serra Branca na microrregião do Cariri no Estado da Paraíba.

\section{REFERÊNCIAS BIBLIOGRÁFICAS}

ALDAZ, L. Caracterização parcial do regime de chuvas do Brasil. Departamento Nacional de Meteorologia, Ministério do Interior. SUDENE, Publicação Técnica, 4, Rio de Janeiro, 1971.

ANDREOLI, R. V.; KAYANO, M. T. A importância relativa do Atlântico tropical sul e Pacífico leste na variabilidade de precipitação do nordeste do Brasil. Revista Brasileira de Meteorologia, v.22, n.1, 63-74, 2007.

ARNAUD, P.; BOUVIER, C.; CISNEROS, L.; DOMINGUEZ, R. Influence of Rainfall spatial variability on flood prediction. Journal of Hydrology, v.1, n.297, p.109-123, 2002.

BRUNETTIA, M.; MAUGERIB, M.; NANNIA, T. Changes in total precipitation, rainy days and extreme events in northeastern Italy. International Journal of Climatology, v.21, n.1, p.861871, 2001.

CHAVES, R.R. Variabilidade da precipitação na região sul do nordeste e sua associação com padrões atmosféricos. Dissertação Mestrado, 159p. - (INPE-7294-TDI/709), 1999.

CHAVES, R. R.; CAVALCANTI, I. F. A. Atmospheric circulation features associated with rainfall variability over southern Northeast Brazil. Monthly Weather Review, v.129, n.10, p.2614-2626, 2001.

DINPASHOH, Y.; FAKHERI-FARD, A.; MOGHADDAN, M.; JAHANBAKHSH, S.; MIRNIA, M. Selection of Variables for the purpose of regionalization of Iran's Precipitation Climate using Multivariate methods. Journal of Hydrology, v.1, n.297, p.109-123, 2004.

EHRENDORFER, M.A. Regionalizaion of Austria's precipitation climate using principal component analysis. Journal of Climatology, v.1, n.7, p.71-89, 1987.

FISCHER, G. R.; DINIZ, G.B.; MARQUES, J.R.Q. Previsão do número de dias de chuva para a metade do Sul do Rio Grande do Sul utilizando a temperatura da superfície do mar (TSM), Revista Brasileira de Meteorologia, v.23, n.2, 143-151, 2008.

GRAEF, F.; HAIGIS, J. Spatial and temporal rainfall variability in the Sahel and its effects on farmers' management strategies. Journal of Arid Environments, v.1, n.48, p.221-231, 2001.

GUTTMAN, N.B.; HOSKING, J.R.M.; WALLIS, J.R. Regional Precipitation quantile values for the continental United States Computed Fron L-Momentes. Journal of Climatology, v.1, n.6, p.2336-2340, 1993.

INNOCENTINI, V.; ARANTES, F. O.; R. J. FERREIRA, R. G. MICHELETO. A agitação marítima no litoral nordeste do Brasil associada aos distúrbios africanos de leste. Revista Brasileira de Meteorologia, v.20, n.3, 367-374, 2005.
MODARRES, R; SILVA, V.P.R. Rainfall trends in arid and semiarid regions of Iran. Journal of Arid Environments, v.70, n.1, p.344-355, 2007.

KOUSKY, V.E. Frontal Influences on Northeast Brasil. Monthly Weather Review, v.1, n.107, p.1140-1153, 1979.

KOUSKY, V.E.; GAN, M.A.Upper troposheric ciclonic vortices in the tropical South Atlantic. Tellus, v.33, n.6, p.538-551, 1981.

RAMOS, R.P.L. Precipitation characteristics in northeast Brazil dry region. Journal Geophysics Research, v.1, n.80, p.16651678, 1975.

RATISBONA, L.R. The climate of Brazil, in W. Schwerdtfeger. Ed., World Survey of Climatology, vol. 12. Climates of Central and South America, Amsterdam, 1976.

SELESHI, Y.; ZANKE, U. Recent changes in rainfall and rainy days in Ethiopia. International Journal of Climatology, v.24, n.8, p.973-983, 2004.

SHAW, A.B. An analysis of the rainfall regimes on the coastal region of Guyana. International Journal of Climatology, v.1, n.7, p.291-302, 1987.

SILVA, V.P.R. On climate variability in Northeast of Brazil. Journal of Arid Environments, v.58, n.1, p.574-596, 2004.

SILVA, V.P.R., AZEVEDO, P.V., BRITO, R.S., CAMPOS, J.H.B.C. Evaluating the urban climate of a typically tropical city of northeastern Brazil. Environmental Monitoring and Assessment, v.161, n.1, p.45-59, 2010.

SILVA, V.P.R.; BELO FILHO, A.F.; SILVA, B.B.; CAMPOS, J.H.B.C. Desenvolvimento de um sistema de estimativa da evapotranspiração de referência. Revista Brasileira de Engenharia Agrícola e Ambiental, v.9, n.4, p.547-553, 2005.

SILVA, V.P.R.; CAVALCANTI, E.P.; NASCIMENTO, M.G.; CAMPOS, J.H.B.C. Análises da precipitação pluvial no Estado da Paraíba com base na teoria da entropia. Revista Brasileira de Engenharia Agrícola e Ambiental, v.7, n.2, p.269-274, 2003.

SILVA, V.P.R.; PEREIRA, E.R.R.; AZEVEDO, P.V.; CAMPOS, J.H.B.C, BRAGA, R.C. Estudo da variabilidade anual e intraanual da precipitação e do número de dias chuvosos no Estado da Paraíba. Revista Ciência da Vida, v.29, n.1, p.50-62, 2009.

SILVA, V.P.R.; SOUSA, F.S.S.; CAVALCANTI, E.P.; SOUZA, E.P.; SILVA, B.B. Teleconnections between sea-surface temperature anomalies and air temperature in northeast Brazil. Journal of Atmospheric and Solar-Terrestrial Physics, v.68, n.7, p.781-792, 2006.

UVO, C. R. B., NOBRE, C. A. Zona de Convergência Intertropical (ZCIT) e a precipitação no Norte do Nordeste do Brasil. CPTEC/INPE, v.4, n.7, 1989.

ZANETTI, S.S.; OLIVEIRA, V.P.S.; PRUSKI, F.F. Validação do modelo Clima BR em relação ao número de dias chuvosos e à precipitação total diária. Engenharia Agrícola, v.26, n.1, p.96-102, 2006.

YAMAZAKI, Y., RAO, V.B. Tropical cloudiness over the South Atlantic Ocean. Journal of the Meteorological Society of Japan, v.55, n.1, p.205-207, 1977. 